Research Article

\title{
Efficacy of Aqueous Extracts from Syzygium aromaticum, Tephrosia vogelii, and Croton dichogamus against Myzus persicae on Brassica oleracea in Northern Tanzania
}

\author{
Nelson Mpumi $\mathbb{D}^{1},{ }^{1}$ Kelvin M. Mtei $\mathbb{D}^{1},{ }^{1}$ Revocatus L. Machunda $\mathbb{D}^{1}{ }^{1}$ \\ and Patrick A. Ndakidemi ${ }^{2}$ \\ ${ }^{1}$ School of Materials, Energy, Water and Environmental Sciences, \\ The Nelson Mandela African Institution of Science and Technology, Arusha, Tanzania \\ ${ }^{2}$ School of Life Sciences and Bioengineering, The Nelson Mandela African Institution of Science and Technology, Arusha, Tanzania
}

Correspondence should be addressed to Nelson Mpumi; nelson.mpumi@nm-aist.ac.tz

Received 21 April 2021; Revised 11 June 2021; Accepted 8 July 2021; Published 19 July 2021

Academic Editor: Nguya K. Maniania

Copyright $(2021$ Nelson Mpumi et al. This is an open access article distributed under the Creative Commons Attribution License, which permits unrestricted use, distribution, and reproduction in any medium, provided the original work is properly cited.

The effectiveness of 1, 5, and 10\% w/v of aqueous extracts of Croton dichogamus, Tephrosia vogelii, and Syzygium aromaticum and their mixture (2.5 and 5\%) was evaluated against Myzus persicae on Brassica oleracea under field conditions. The synthetic chemical insecticide, chlorpyrifos, was used as positive control, and water and water plus soap were used as negative controls. Aqueous extracts significantly $(P \leq 0.05)$ lowered $M$. persicae population compared with negative controls. The $5 \%$ of the aqueous extract from mixed plants and $10 \%$ of each plant used in this study significantly $(P \leq 0.01)$ reduced aphid, $M$. persicae population comparable to chlorpyrifos in 2019 and 2020. However, the 1 and 5\% concentrations of aqueous extracts of C. dichogamus, T. vogelii, and S. aromaticum and $2.5 \%$ of aqueous extracts from the mixed plants significantly lowered the population of M. persicae compared with negative controls in 2019 and 2020 wet seasons. The weekly observations revealed that, at weeks $1,2,3$, 4 , and 5 after application of treatments, the population of $M$. persicae differed significantly $(P \leq 0.05)$. Also, the aqueous extracts from the mixed plants at $5 \%$ concentrations significantly $(P \leq 0.01)$ reduced $M$. persicae population as compared with other treatments. It was as effective as synthetic chemical pesticide (chlorpyrifos). Also, 1 and 5\% of $C$. dichogamus, T. vogelii, and $S$. aromaticum and the $2.5 \%$ of aqueous extracts from the mixed plants significantly reduced the population of $M$. persicae for all 6 weeks of study compared with negative controls. Therefore, these pesticidal plants can be recommended to smallholder farmers for the control of $M$. persicae in B. oleracea crops.

\section{Introduction}

Smallholder farmers in African countries grow cabbage, Brassica oleracea var. capitata L., intensively for subsistence and income source [1]. B. oleracea is a popular leafy green vegetable crop grown as an annual plant $[2,3]$. Essential vitamins such as vitamins $\mathrm{K}$ and $\mathrm{C}$, nutritional fibres, and elements, particularly manganese and potassium, are found in Brassica species $[4,5]$.

Despite the economical and nutritional values of B. oleracea, the production is constrained by damage caused by numerous insect pests [6]. The nutritional contents in $B$. oleracea attract numerous phytophagous insects which feed on and cause severe damages and economic losses [3, 7], among which aphids are the most common pests [5]. The population abundance of green peach aphids, Myzus persicae L. (Hemiptera: Aphididae), is the highest in the tropical areas and is among the most destructive insect pests of the cruciferous vegetables on the garden of smallholder farmers' farms which reduce the quality and the marketability of cruciferous vegetables [2]. M. persicae is found globally and may be present in a particular area at any time all over the year [8]. M. persicae has a pale green colour and winged and wingless forms [9]. The winged form of $M$. persicae possesses a distinct dark patch nearby the tip of the abdomen, while the wingless form does not have dark patch [10]. The 
cruciferous vegetable crops support the growth and development of M. persicae [11]. They feed on fruits, flowers, buds, leaves, and stems, with piercing-sucking mouthparts resulting in huge damage to the crops [12]. The feeding mechanisms of this nature can destroy the vegetable crop's structures, and the crops become stunted, yellowed, and distorted [10]. The actively growing regions of the crops and the tender plant tissues are usually damaged by large continuous colonies of green peach aphid populations [10]. According to Valenzuela and Hoffmann [13] and de Little and Umina [14], M. persicae spreads brutally damaging viruses such as cucumber mosaic, watermelon mosaic, cauliflower mosaic, lettuce mosaic, potyviruses in pepper, potato leafroll, and turnip mosaic. Those viruses severely affect the health and the proper process of growing and developing Brassica species crops. The destruction effects triggered by $M$. persicae are indicated by large continuous colonies of them living and sucking plant sap on the underneath of the leaves $[14,15]$.

In African countries, the management of $M$. persicae is inefficient due to the limited awareness and availability of synthetic pesticides. Therefore, most smallholder farmers in African countries favour cultural practices such as row spacing, crop rotation, sowing date, and weed control to reduce the infestation of the crop caused by green peach aphids [6]. However, the cultural practices are less effective in controlling $M$. persicae on the garden field to protect $B$. oleracea. The natural enemies, for instance, ladybird beetles, Coccinellidae (Coleoptera: Coccinellidae) and Cotesia plutellae L. (Kurdjumov) (Hymenoptera: Braconidae), that feed on green peach aphids can help reduce the infestation of $B$. oleracea by $M$. persicae. Moreover, the natural enemies are less efficient in reducing large colonies of $M$. persicae in crops. Therefore, to effectively control and manage $M$. persicae on $B$. oleracea crops, the smallholder farmers in Africa depend heavily on synthetic chemical insecticide applications [10]. However, heavy dependence on synthetic insecticides has resulted in the development of resistance [16]. For instance, $M$. persicae has exhibited resistance towards a broad range of frequently used synthetic chemical insecticides such as decamethrin, cypermethrin, malathion, and lamda-cyhalothrine [17]. This has forced the African smallholder farmers to increase the rate and concentrations of synthetic chemical insecticides [12]. Moreover, heavy application of synthetic chemical insecticides endangers the health of human beings and other nontarget organisms [6]. Thus, pesticidal plants such as Cupscum frutensces, Annona squamosa, Allium sativa, Tephrosia vogelii, and Azadirachta indica are promising substitutes due to the successful effectiveness in the control of pests in cereal crops $[18,19]$. The botanicals have antifeedant, toxicity, deterrent, and insecticidal effects. They are affordable [20], their preparations and use are easy [18], and they environmentally friendly [21]. Moreover, botanicals degrade quickly in the presence of moisture, air, and light from the sun and decomposed readily by detoxifying enzymes, and many botanicals possess low dangers to nontarget organisms $[18,22]$. In this study, C. dichogamus, $T$. vogelii, and $S$. aromaticum were selected based on traditional knowledge whereby many African smallholder farmers apply T. vogelii as an insecticide to control ticks, lice, and flies on animals. Additionally, the concoction from T. vogelii leaves is used as traditional medicine for skin disease treatments [23, 24]. Also, S. aromaticum contains eugenol, a spicy chemical compound $[25,26]$ which has been reported to be used as an insect repellent and antifeedant [27]. Similarly, the indigenous people in most African countries use concoctions from Croton species leaves and stem barks as traditional medications for relieving various illnesses in human beings such as stultification, tumour, and stomachache [28]. Consequently, the present study was performed to assess the effectiveness of aqueous extracts from $C$. dichogamus, T. vogelii, and S. aromaticum against Myzus persicae on the Brassica oleracea crop.

\section{Materials and Methods}

2.1. Study Sites. This study used the methods of Mpumi et al. [6] with little modifications. Field experiment was performed between March and August in 2019 and 2020 wet seasons in the northern part of Tanzania to study the effectiveness of aqueous extracts obtained from S. aromaticum, $T$. vogelii, and $C$. dichogamus against $M$. persicae on $B$. oleracea. The experimental sites were situated in two regions in Tanzania, Arusha and Kilimanjaro regions. The study was established in the Tengeru site located at latitude $3^{\circ} 23^{\prime} 4.5^{\prime \prime} \mathrm{S}$ and longitude $36^{\circ} 48^{\prime} 26.7^{\prime \prime} \mathrm{E}$ at an elevation of $1262 \mathrm{~m}$ above sea level in the Arusha region [6]. The temperature and rainfall precipitation ranged from $0 \mathrm{~mm}$ to $287 \mathrm{~mm}$ and 25.9 to $34.5^{\circ} \mathrm{C}$, respectively, in the same year at the Tengeru experimental site [6], and humidity ranged from 78 to $80 \%$. In the Kilimanjaro region, the study was established in the Boro experimental site situated at latitude $3^{\circ} 17^{\prime} 31.5^{\prime \prime} \mathrm{S}$ and longitude $37^{\circ} 17^{\prime} 49.1^{\prime \prime} \mathrm{E}$ and an elevation of $1078 \mathrm{~m}$ above sea level. At the Boro experimental site, the rainfall precipitation ranged from $5 \mathrm{~mm}$ to about $883 \mathrm{~mm}$, and the temperature ranged from 22 to $30.2^{\circ} \mathrm{C}$ during the study period, March to August 2019 wet season [6]. In the 2020 wet season, the meteorological data of rainfall and temperature were observed from the experimental locations.

\subsection{Collection, Drying, and Grinding of Plant Materials.} Leaves of $C$. dichogamus and $T$. vogelii were collected from various parts in Manyara, Arusha, and Kilimanjaro regions in Tanzania. However, the flower buds of $S$. aromaticum were collected in the Tanga Region, Tanzania. Then, the leaves of $T$. vogelii and $C$. dichogamus were thoroughly washed using tap water and dried in the shade at room temperature for one week. Then, the flower buds and the dried leaves collected in this study were ground by using a grinding mill into a powder form. The obtained powder was dissolved into water mixed with $0.1 \%$ soap to obtain the aqueous extracts intended for experimentation. Liquid soap aids the extraction of compounds present in the pesticidal plant materials which are not water soluble. Secondly, it assists in spreading the extracts on top of the leaves of plants more efficiently during the spraying of the treatments. 
2.3. Land Preparation and Transplanting. Clearance and preparation of the land were carried out before the transplanting of seedlings. The land was ploughed and harrowed before seedling transplanting at both experimental sites using a plough and a hand hoe in both seasons. The seeds of B. oleracea were sown near the study plots in March 2019 and 2020 wet seasons. After a month and one week, the seedlings were removed and transplanted into the study plots established from the middle of April to August (2019 and 2020) wet seasons at both experimental study sites. The spacing of $B$. oleracea seedling crops was $50 \mathrm{~cm}$ between the rows and $45 \mathrm{~cm}$ within the rows in the study plots. The plot size was $2.0 \mathrm{~m} \times 2.5 \mathrm{~m}$ at both experimental sites. The distance from one plot to another plot was $0.5 \mathrm{~m}$. Each treatment plot contained $12 \mathrm{~B}$. oleracea crops. Watering was carried out two times a day in the morning and the evening for one week after transplanting and then once a day throughout the growing of the crop.

\subsection{Experimental Design and Treatment Preparations.} The experiment consisted of 14 treatments, was replicated four times, and was designed in a Randomized Complete Block Design (RCBD). The experiment involved the aqueous extracts from C. dichogamu, T. vogelii, and S. aromaticum; water alone and water plus soap were negative controls, and chlorpyrifos was a positive control. The aqueous extracts at $1 \%, 5 \%$, and $10 \% \mathrm{w} / \mathrm{v}$ concentrations were prepared from each plant to treat $B$. oleracea crop against $M$. persicae in the garden field. Therefore, $10 \%, 5 \%$, and $1 \%$ of aqueous extracts from pesticidal plants were prepared by dissolving $100 \mathrm{~g}$, $50 \mathrm{~g}$, and $10 \mathrm{~g}$ of powder into one litre of water containing $0.1 \%$ soap, respectively. The soap was purchased from the shop in Arusha city manufactured by Sterling Dexi company, Tanzania, and it was a liquid soap known as orange fresh. The mixture was soaked and allowed to stay for 24 hours at room temperature [12]. Then, after 24 hours, the mixture was filtered using a clean piece of cotton cloth to get the aqueous extracts.

Aqueous extracts with a combination of pesticidal plants were prepared by mixing $25 \mathrm{~g}$ and $50 \mathrm{~g}$ of each plant (T. vogelii, C. dichogamus, and S. aromaticum) in equal ratio and dissolved in one litre of water (w/v) separately to make $2.5 \%$ and $5 \%$ concentrations, respectively, and was replicated four times making 8 treatment plots. Therefore, the onstation field contained 56 treatment plots at both experimental sites in 2019 and 2020 wet seasons. Mixing of the pesticidal plants was performed to evaluate the synergistic insecticidal action of extracts from $S$. aromaticum, C. dichogamus, and T. vogelii against $M$. persicae pests on B. oleracea crop field.

2.5. Treatment Applications. The pesticidal plant extracts and controls were applied to the B. oleracea crops in the field garden at the interval of 7 days during the growing of the crops. The concentration of chlorpyrifos was prepared and sprayed based on the recommendations of manufacturers. The treatments were applied on the topmost and underneath of the leaves of $B$. oleracea crop by using a $2 \mathrm{~L}$ sprayer in the evening hours throughout the growing season [6]. The spraying was performed during the evening hours to avoid direct sunlight, which may cause the breakdown of bioactive compounds of the botanicals. About $250 \mathrm{ml}$ of the aqueous extract at both experimental sites was sprayed on a plot [29]. Before refilling the sprayer with another treatment for application, it was cleaned thoroughly with water and soap.

2.6. M. persicae Population Assessment. Assessment of insects was performed a day before the spray of the treatments. Five inner $B$. oleracea crops were randomly selected inside the plots to assess $M$. persicae weekly. The number of $M$. persicae was obtained by scoring its population using a modified method [30] as $0=$ absent, $1=\mathrm{a}$ few scattered individuals, $2=\mathrm{a}$ few isolated small colonies, $3=$ several isolated small colonies, $4=$ large isolated colonies, and $5=$ large continuous colonies. The natural enemies such as parasitoid wasp (Cotesia plutellae) and ladybird beetle (Cocinella septempunctata) were just counted.

2.7. Analysis of Data. Statistica 8.0 software package version 7 program was used for statistical analysis of the collected data. Two-way ANOVA statistical analysis was conducted on split plot sites and treatments. Three-way ANOVA statistical analysis was performed on split plot sites, seasons, and treatments. The comparison of the treatment means at the $P=0.05$ level of significance with Fisher's Least Significance Difference (LSD) was applied.

\section{Results and Discussion}

\subsection{Results}

3.1.1. Temperature and Rain Precipitation of the Study Sites in 2020. Figures 1(a) and 1(b) show the temperature and rainfall precipitations of the two experimental study sites in the 2020 wet season. The maximum temperature at the Tengeru experimental site in the 2020 wet season was higher relative to that of the Boro experimental site throughout the study period (Figures 1(a) and 1(b)). It was observed that the maximum temperature of the Tengeru experimental site in the 2020 wet season was higher relative to those of the Boro experimental site throughout the study period (Figures 1(a) and $1(\mathrm{~b})$ ). However, the minimum temperatures varied relatively between the two experimental sites. Therefore, the Tengeru experimental site was warmer than the Boro experimental site throughout the study period in the 2020 wet season. Specifically, the rainfall precipitations were higher in March, July, August, and September at the Tengeru experimental site than at the Boro experimental site in the 2020 wet season. In February, April, and June, the rainfall precipitations were relatively the same in both experimental sites in the 2020 wet season. The mean maximum and minimum temperatures of the Boro experimental site were 24.3 and $15.7^{\circ} \mathrm{C}$, respectively, while at the Tengeru experimental site, the mean maximum and minimum temperatures were 28.0 and $17.1^{\circ} \mathrm{C}$, respectively. The mean rainfall precipitations at Tengeru and Boro experimental sites were 


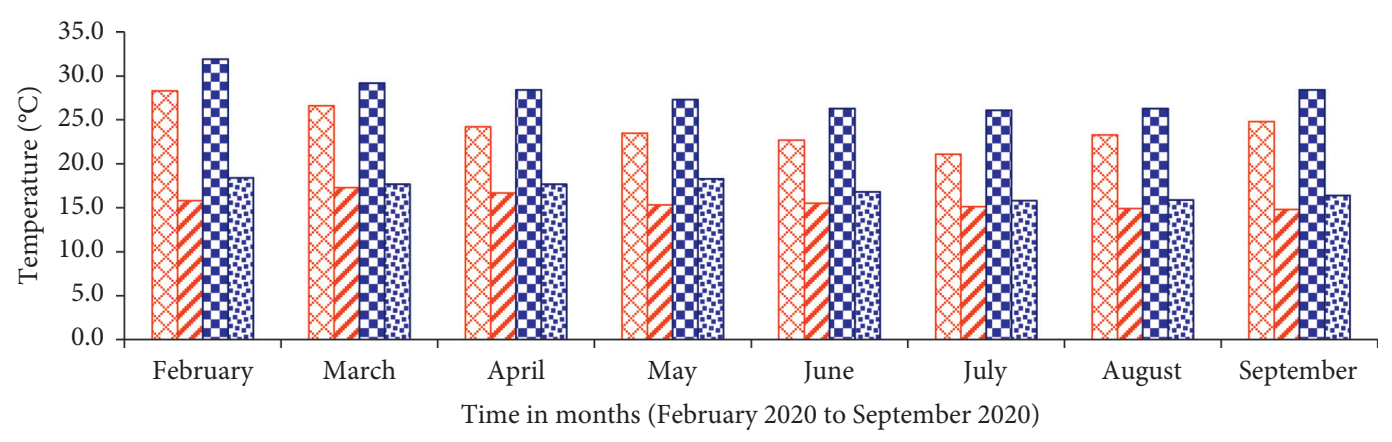

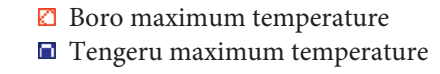

B Tengeru maximum temperature
○ Boro minimum temperature

回 Tengeru minimum temperature

(a)

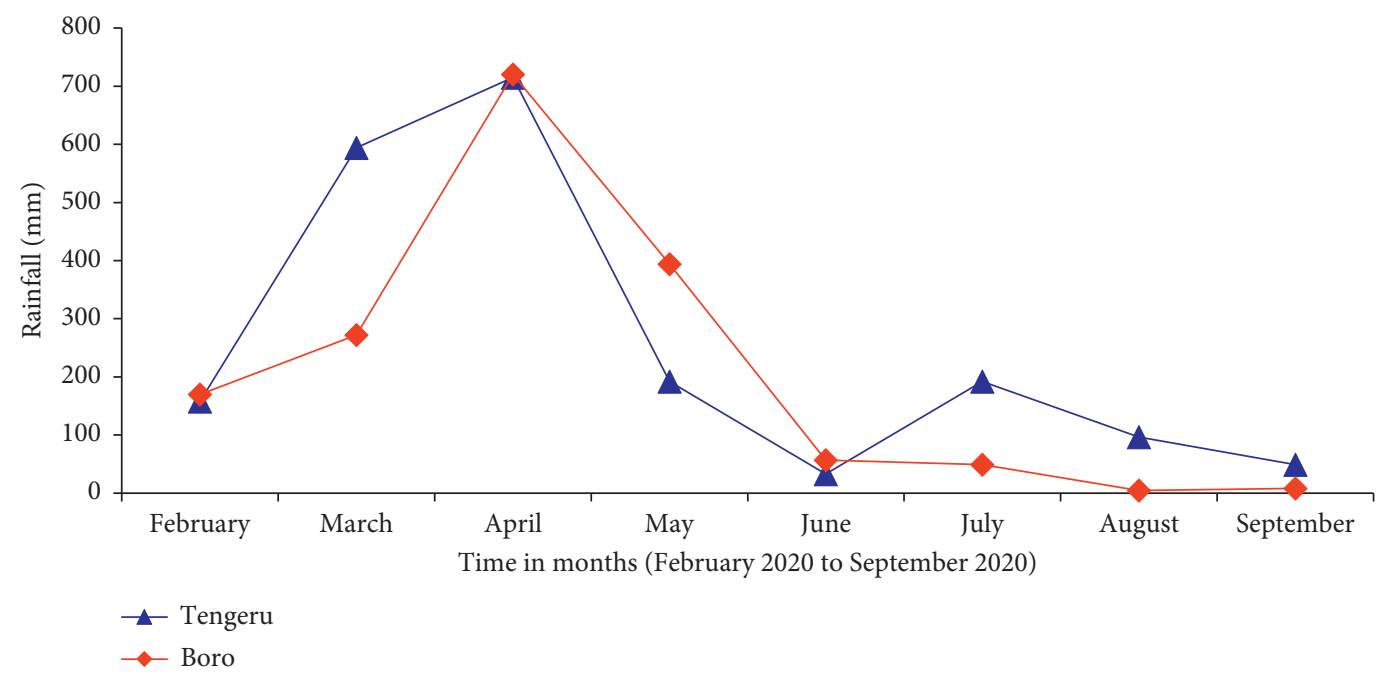

(b)

Figure 1: Temperatures (a) and rainfall precipitations (b) at Boro and Tengeru experimental sites during the field experiments in the 2020 wet season.

253.7 and $209.4 \mathrm{~mm}$, respectively. Those weather conditions could have been affected effectively by either lowering or increasing the population of $M$. persicae on B. oleracea at the experimental sites.

3.1.2. The Effects of Treatments on the Abundance of M. persicae. M. persicae was observed infesting the $B$. oleracea two weeks after transplanting, and the mean population increased progressively with time (Table 1). Table 2 describes the abundance of $M$. persicae per plant following application of the treatments at the two experimental sites in 2019 and 2020 wet seasons. Population abundance was significantly $(P \leq 0.05)$ the same in the two experimental sites (Table 2) in both 2019 and 2020 wet seasons. Moreover, the study revealed that the aqueous extracts of plants and synthetic chemical pesticide (chlorpyrifos) differed significantly $(P \leq 0.05)$ relative to negative controls in reduction of $M$. persicae populations in both seasons (Table 2). The 5\% concentration of the aqueous extract from the mixed plants and the $10 \%$ of the aqueous extracts from each plant possessed a significantly $(P \leq 0.01)$ lower population of $M$. persicae as the synthetic chemical pesticide (chlorpyrifos) in 2019 and 2020 wet seasons at both experimental sites (Table 2). However, 1 and $5 \%$ of the aqueous extracts of $C$. dichogamus, $T$. vogelii, and S. aromaticum from each plant and $2.5 \%$ concentration of the aqueous extracts from the mixed plants significantly lowered the population of $M$. persicae compared with negative controls for both 2019 and 2020 wet seasons (Table 2).

Table 1 describes the weekly observations of the population of $M$. persicae at the two experimental sites in both wet seasons of 2019 and 2020. The mean population of M. persicae was significantly $(P \leq 0.01)$ higher in 2020 wet season than in 2019 season. However, in week 1 after application of the treatments, the population was significantly $(P \leq 0.01)$ higher $(0.66)$ in the 2019 wet season compared with the 2020 wet season (0.52). In week 2 after application of the treatments, the mean population of $M$. persicae was significantly the same. Similarly, the mean population of $M$. persicae was significantly $(P \leq 0.01)$ higher $(1.15$ and 0.74$)$ at the Tengeru experimental site than at the Boro experimental site ( 0.76 and 0.59$)$ in week 1 before treatment and 
TABLE 1: Mean population of M. persicae per crop in response to treatments applied weekly.

\begin{tabular}{|c|c|c|c|c|c|c|}
\hline \multirow{2}{*}{ Site and treatments } & \multirow{2}{*}{$\begin{array}{c}\text { Week } 1 \text { before } \\
\text { Treatment }\end{array}$} & \multicolumn{5}{|c|}{ Weeks after treatment } \\
\hline & & 1 & 2 & 3 & 4 & 5 \\
\hline \multicolumn{7}{|l|}{ Seasons } \\
\hline Wet season 1 (2019) & $0.87 \pm 0.05 b$ & $0.66 \pm 0.06 \mathrm{a}$ & $0.55 \pm 0.06 \mathrm{a}$ & $0.49 \pm 0.06 b$ & $0.51 \pm 0.08 b$ & $0.57 \pm 0.09 b$ \\
\hline Wet season $2(2020)$ & $1.05 \pm 0.05 \mathrm{a}$ & $0.52 \pm 0.04 b$ & $0.54 \pm 0.05 a$ & $0.67 \pm 0.07 a$ & $0.76 \pm 0.07 a$ & $0.76 \pm 0.08 \mathrm{a}$ \\
\hline \multicolumn{7}{|l|}{ Site } \\
\hline Tengeru & $1.15 \pm 0.05 \mathrm{a}$ & $0.62 \pm 0.05 a$ & $0.55 \pm 0.06 \mathrm{a}$ & $0.58 \pm 0.07 a$ & $0.68 \pm 0.08 \mathrm{a}$ & $0.74 \pm 0.09 a$ \\
\hline Boro & $0.76 \pm 0.04 \mathrm{~b}$ & $0.55 \pm 0.05 \mathrm{a}$ & $0.54 \pm 0.05 a$ & $0.57 \pm 0.07 \mathrm{a}$ & $0.59 \pm 0.07 \mathrm{a}$ & $0.59 \pm 0.08 b$ \\
\hline \multicolumn{7}{|l|}{ Treatments } \\
\hline $\mathrm{W}$ & $1.165 \pm 0.09 a$ & $1.71 \pm 0.17 \mathrm{a}$ & $1.86 \pm 0.19 a$ & $2.15 \pm 0.16 \mathrm{a}$ & $2.44 \pm 0.21 \mathrm{a}$ & $2.67 \pm 0.18 \mathrm{a}$ \\
\hline $\mathrm{W}+\mathrm{s}$ & $0.89 \pm 0.11 \mathrm{a}$ & $1.54 \pm 0.15 \mathrm{a}$ & $1.42 \pm 0.14 \mathrm{ab}$ & $1.93 \pm 0.23 a$ & $2.21 \pm 0.16 \mathrm{a}$ & $2.76 \pm 0.14 \mathrm{a}$ \\
\hline S. p & $1.08 \pm 0.15 \mathrm{a}$ & $0.14 \pm 0.04 \mathrm{f}$ & $0.18 \pm 0.09$ fgh & $0.18 \pm 0.07 \mathrm{ef}$ & $0.21 \pm 0.07 \mathrm{cde}$ & $0.18 \pm 0.05 \mathrm{ef}$ \\
\hline C. $d(1 \%)$ & $1.13 \pm 0.15 a$ & $0.71 \pm 0.08 \mathrm{~b}$ & $0.64 \pm 0.12 \mathrm{~cd}$ & $0.54 \pm 0.07 \mathrm{bcd}$ & $0.60 \pm 0.07 b$ & $0.54 \pm 0.06 \mathrm{bc}$ \\
\hline C. $d(5 \%)$ & $0.83 \pm 0.13 a$ & $0.45 \pm 0.04 \mathrm{~cd}$ & $0.47 \pm 0.05 \mathrm{cde}$ & $0.39 \pm 0.06 \mathrm{cde}$ & $0.39 \pm 0.05 \mathrm{bcde}$ & $0.36 \pm 0.05 \mathrm{cde}$ \\
\hline C. $d(10 \%)$ & $0.96 \pm 0.13 a$ & $0.46 \pm 0.04 \mathrm{~cd}$ & $0.40 \pm 0.08 \mathrm{cdef}$ & $0.20 \pm 0.05 \mathrm{ef}$ & $0.38 \pm 0.07 \mathrm{bcde}$ & $0.35 \pm 0.05 \mathrm{cdef}$ \\
\hline S. $a(1 \%)$ & $0.98 \pm 0.10 \mathrm{a}$ & $0.60 \pm 0.08 b c$ & $0.56 \pm 0.07 \mathrm{~cd}$ & $0.61 \pm 0.07 b$ & $0.63 \pm 0.12 b$ & $0.66 \pm 0.09 b$ \\
\hline S. $a(5 \%)$ & $0.81 \pm 0.11 \mathrm{a}$ & $0.45 \pm 0.06 \mathrm{~cd}$ & $0.45 \pm 0.06 \mathrm{cde}$ & $0.39 \pm 0.06 \mathrm{bcde}$ & $0.46 \pm 0.10 \mathrm{bcd}$ & $0.31 \pm 0.05 \mathrm{cdef}$ \\
\hline S. $a(10 \%)$ & $0.94 \pm 0.12 \mathrm{a}$ & $0.36 \pm 0.04 \mathrm{def}$ & $0.31 \pm 0.06 \mathrm{efgh}$ & $0.28 \pm 0.05 \mathrm{def}$ & $0.20 \pm 0.05 \mathrm{de}$ & $0.24 \pm 0.04 \mathrm{ef}$ \\
\hline T. $v(1 \%)$ & $0.88 \pm 0.15 a$ & $0.50 \pm 0.07 \mathrm{bcd}$ & $0.58 \pm 0.06 \mathrm{~cd}$ & $0.55 \pm 0.09 b c$ & $0.49 \pm 0.09 b c$ & $0.48 \pm 0.10 \mathrm{bcd}$ \\
\hline T. $v(5 \%)$ & $0.93 \pm 0.16 a$ & $0.41 \pm 0.07 \mathrm{cde}$ & $0.35 \pm 0.05 \mathrm{defg}$ & $0.33 \pm 0.07 \mathrm{cdef}$ & $0.29 \pm 0.06 \mathrm{bcde}$ & $0.24 \pm 0.05 \mathrm{ef}$ \\
\hline T. $v(10 \%)$ & $1.04 \pm 0.16 a$ & $0.29 \pm 0.04 \mathrm{def}$ & $0.15 \pm 0.02 \mathrm{fg}$ & $0.16 \pm 0.03 \mathrm{ef}$ & $0.16 \pm 0.04 f$ & $0.17 \pm 0.04 \mathrm{ef}$ \\
\hline M.p. $(2.5 \%)$ & $0.88 \pm 0.12 \mathrm{a}$ & $0.38 \pm 0.08 \mathrm{cde}$ & $0.20 \pm 0.03 \mathrm{fgh}$ & $0.30 \pm 0.07 \mathrm{cdef}$ & $0.26 \pm 0.07 \mathrm{cde}$ & $0.25 \pm 0.07 \mathrm{def}$ \\
\hline M. p. (5\%) & $0.96 \pm 0.10 \mathrm{a}$ & $0.20 \pm 0.04 \mathrm{ef}$ & $0.10 \pm 0.03 \mathrm{~h}$ & $0.12 \pm 0.03 f$ & $0.14 \pm 0.04 \mathrm{f}$ & $0.13 \pm 0.04 \mathrm{f}$ \\
\hline 3-way ANOVA & (F-statistics) & & & & & \\
\hline Season $(\mathrm{S})$ & $8.40^{* *}$ & $10.86^{* *}$ & $0.03 \mathrm{~ns}$ & $15.59^{* * *}$ & $26.84^{* * *}$ & $24.98^{* * *}$ \\
\hline Site (L) & $36.90^{* * *}$ & $3.15 \mathrm{~ns}$ & $0.00 \mathrm{~ns}$ & $0.06 \mathrm{~ns}$ & $3.33 \mathrm{~ns}$ & $15.91^{* * *}$ \\
\hline Treatments (T) & $0.77 \mathrm{~ns}$ & $34.63^{* * *}$ & $37.92^{* * *}$ & $54.88^{* * *}$ & $64.37^{* * *}$ & $146.59^{* * *}$ \\
\hline $\mathrm{S}^{*} \mathrm{~L}$ & $0.07 \mathrm{~ns}$ & $4.83^{* * *}$ & $14.93^{* * *}$ & $4.77^{*}$ & $9.39^{* *}$ & $7.82^{* *}$ \\
\hline $\mathrm{S}^{*} \mathrm{~T}$ & $0.31 \mathrm{~ns}$ & $2.46^{* *}$ & $1.32 \mathrm{~ns}$ & $1.61 \mathrm{~ns}$ & $1.42 \mathrm{~ns}$ & $1.98 \mathrm{~ns}$ \\
\hline $\mathrm{L}^{*} \mathrm{~T}$ & $0.66 \mathrm{~ns}$ & $0.34 \mathrm{~ns}$ & $0.74 \mathrm{~ns}$ & $0.89 \mathrm{~ns}$ & $0.74 \mathrm{~ns}$ & $1.01 \mathrm{~ns}$ \\
\hline $\mathrm{S}^{*} \mathrm{~L}^{*} \mathrm{~T}$ & $0.86 \mathrm{~ns}$ & $0.90 \mathrm{~ns}$ & $2.67^{* *}$ & $2.37 \mathrm{~ns}$ & $0.79 \mathrm{~ns}$ & $1.76 \mathrm{~ns}$ \\
\hline
\end{tabular}

Each value is a mean \pm standard error of sixteen replicates, ${ }^{*},{ }^{* *}$, and ${ }^{* * *}$ : significant at $P \leq 0.05, P \leq 0.01$, and $P \leq 0.001$, respectively, and ns means not significant. Means within the same column followed by the same letter (s) are not significantly different at $P=0.05$ from each other using Fisher's Least significant Difference (LSD) test.

Table 2: Mean population of $M$. persicae per crop in response to treatments applied.

\begin{tabular}{|c|c|c|}
\hline \multirow{2}{*}{ Site and treatments } & \multicolumn{2}{|c|}{ Seasons } \\
\hline & 2019 wet season & 2020 wet season \\
\hline \multicolumn{3}{|l|}{ Site } \\
\hline Tengeru & $0.59 \pm 0.11 \mathrm{a}$ & $0.67 \pm 0.08 \mathrm{a}$ \\
\hline Boro & $0.51 \pm 0.08 \mathrm{a}$ & $0.63 \pm 0.09 a$ \\
\hline \multicolumn{3}{|l|}{ Treatments } \\
\hline Water & $2.27 \pm 0.25 \mathrm{a}$ & $2.07 \pm 0.12 \mathrm{a}$ \\
\hline Water + soap & $1.90 \pm 0.24 \mathrm{ab}$ & $2.05 \pm 0.09 \mathrm{a}$ \\
\hline Synthetic pesticide & $0.21 \pm 0.10 \mathrm{de}$ & $0.11 \pm 0.03 \mathrm{~g}$ \\
\hline C. dichogamus (1\%) & $0.64 \pm 0.08 b c$ & $0.57 \pm 0.05 b c$ \\
\hline C. dichogamus $(5 \%)$ & $0.35 \pm 0.03 \mathrm{de}$ & $0.48 \pm 0.03 c d$ \\
\hline C. dichogamus (10\%) & $0.39 \pm 0.08 \mathrm{cde}$ & $0.33 \pm 0.03 \mathrm{efg}$ \\
\hline S. aromaticum $(1 \%)$ & $0.44 \pm 0.04 \mathrm{~cd}$ & $0.79 \pm 0.09 \mathrm{~b}$ \\
\hline S. aromaticum (5\%) & $0.32 \pm 0.05 \mathrm{de}$ & $0.51 \pm 0.04 c d$ \\
\hline S. aromaticum $(10 \%)$ & $0.23 \pm 0.03 \mathrm{de}$ & $0.33 \pm 0.04 \mathrm{efg}$ \\
\hline T. vogelii $(1 \%)$ & $0.32 \pm 0.02 \mathrm{de}$ & $0.72 \pm 0.05 b$ \\
\hline T. vogelii $(5 \%)$ & $0.21 \pm 0.04 \mathrm{de}$ & $0.44 \pm 0.04 \mathrm{de}$ \\
\hline T. vogelii $(10 \%)$ & $0.15 \pm 0.02 \mathrm{de}$ & $0.23 \pm 0.02 \mathrm{fg}$ \\
\hline Mixed plants $(2.5 \%)$ & $0.20 \pm 0.05 \mathrm{de}$ & $0.36 \pm 0.06 \mathrm{def}$ \\
\hline Mixed plants (5\%) & $0.12 \pm 0.03 \mathrm{e}$ & $0.16 \pm 0.04 \mathrm{~g}$ \\
\hline 2-way ANOVA & (F-statistics) & \\
\hline
\end{tabular}


TABLE 2: Continued.

\begin{tabular}{lcc}
\hline Site and treatments & & Seasons \\
& 2019 wet season & 2020 wet season \\
\hline Site & $2.51 \mathrm{~ns}^{* * *}$ & $2.47 \mathrm{~ns}^{* * *}$ \\
Treatments & 42.19 & 132.71 \\
Location ${ }^{*}$ treatments & $1.18 \mathrm{~ns}$ & $2.18 \mathrm{~ns}$ \\
\hline
\end{tabular}

Each value is a mean \pm standard error of eight replicates, ${ }^{*},{ }^{* *}$, and ${ }^{* * *}$ : significant at $P \leq 0.05, P \leq 0.01$, and $P \leq 0.001$, respectively, and ns means not significant. Means within the same column followed by the same letter (s) are insignificantly at $P=0.05$ from each other using Fisher's Least significant Difference (LSD) test.

week 5 after treatment applications in both wet seasons, respectively (Table 1). However, on weeks $1,2,3$, and 4 after treatment application, the population of $M$. persicae was statistically the same at the two experimental sites in both wet seasons (Table 1). The present study revealed that the aqueous extracts applied were effective against $M$. persicae in both seasons. On week 1 before application of the treatments, the mean population of $M$. persicae on different plots was random and was insignificant $(P>0.05)$ among the plots in the field. However, at the $1^{\text {st }}, 2^{\text {nd }}, 3^{\text {rd }}, 4^{\text {th }}$, and $5^{\text {th }}$ week of application of the treatments, the population of $M$. persicae differed significantly $(\leq 0.05)$ from one treatment plot to another (Table 1). Moreover, the study revealed that the 5\% concentration of the aqueous extracts from the mixed plants possessed a significantly $(P \leq 0.01)$ lower population of $M$. persicae $(0.20,0.10,0.12,0.14$, and 0.13$)$ compared to other treatments on weeks $1,2,3,4$, and 5 of the treatments. It was significantly as effective as the synthetic pesticide (chlorpyrifos) $(0.14,0.18,0.18,0.21$, and 0.18$)$ on weeks 1,2 , 3,4 , and 5 of the treatments, respectively. The $1 \%$ and $5 \%$ of the aqueous extracts of $C$. dichogamus, $T$. vogelii, and S. aromaticum and $2.5 \%$ concentration of the aqueous extracts from the mixed plants significantly lowered the population of $M$. persicae relative to water alone and water plus soap for both seasons (Table 1).

The interactions among of the experimental sites' weather conditions, treatments, and seasons significantly $(P \leq 0.05)$ affected the population of $M$. persicae relative to negative controls (water and water plus soap) in the plots (Table 1; Figures 1 and 2). It was observed that the population abundance of $M$. persicae decreased significantly in the treated plots relative to the negative controls (water and water plus soap) in both seasons.

At the Tengeru experimental site, the mean population of $M$. persicae was relatively higher on week 1 and 2 in the 2019 wet season compared to the 2020 wet season (Figure 1). But, from weeks 3, 4, and 5, the population of $M$. persicae was relatively lower in the 2019 wet season at the Tengeru experimental site relative to the 2020 wet season (Figure 1). However, at the Boro experimental site, the population of M. persicae was significantly higher in the 2020 wet season compared with the 2019 wet season in weeks 2, 3, 4, and 5 except in week 1 , whereby the population of $M$. persicae was significantly higher in the 2019 wet season relative to the 2020 wet season.

Similarly, the interactions among of the experimental sites' weather conditions, treatments, and seasons significantly $(P \leq 0.05)$ affected the population of $M$. persicae relative to negative controls (water alone and water plus soap) in the plots in week 2 after the experimental treatments (Table 1; Figure 3).

3.1.3. The Abundance and Response of Cocinella septempunctata to the Treatments. Among the natural enemies of $M$. persicae observed during the study period from the March 2019 and 2020 wet season to August 2019 and 2020, Cocinella septempunctata was present in higher numbers compared to other natural enemies such as Cotesia plutellae. The population dynamic of $C$. septempunctata following application of treatments is presented in Figure 4. The aqueous plant extracts had higher number of C. septempunctata compared with the synthetic pesticide at both experimental sites in both seasons. The population of C. septempunctata was higher at the Tengeru experimental site than the Boro site in 2019 (Figure 4(a)), while it was the opposite in the 2020 season (Figure 4(a)). In both 2019 and 2020 wet seasons, the aqueous plant extracts had higher number of C. septempunctata compared to the synthetic chemical pesticide (Figure 4(b)).

\section{Discussion}

$M$. persicae started to infest the crop in the field from the $2^{\text {nd }}$ week after transplanting of seedlings at experimental sites in both seasons. The population of $M$. persicae differed significantly between the seasons, with the highest population in the 2020 season. This difference could be attributed by the variations of weather conditions at both experimental sites. Extreme weather conditions such as heavy rainfall, temperatures, and high humidity have been reported to influence population abundance of the insects in their ecosystems [5]. From this study, the mean maximum and minimum temperatures of the Boro experimental site in the 2019 wet season were 25.2 and $16.1^{\circ} \mathrm{C}$, respectively, while those of the Tengeru experimental site were 29.5 and $16.9^{\circ} \mathrm{C}$, respectively [6]. The mean rainfall precipitations of Boro and Tengeru experimental sites were 148.05 and $70.81 \mathrm{~mm}$, respectively [6]. Similarly, in the 2020 wet season, the mean maximum and minimum temperatures of the Boro experimental site were 24.3 and $15.7^{\circ} \mathrm{C}$, respectively, while at the Tengeru experimental site, the mean maximum and minimum temperatures were 28.0 and $17.1^{\circ} \mathrm{C}$, respectively. The mean rainfall precipitations at Tengeru and Boro experimental sites were 253.70 and $209.40 \mathrm{~mm}$, respectively. It was clear that higher rainfall precipitation was observed during the study period in 
Week 1

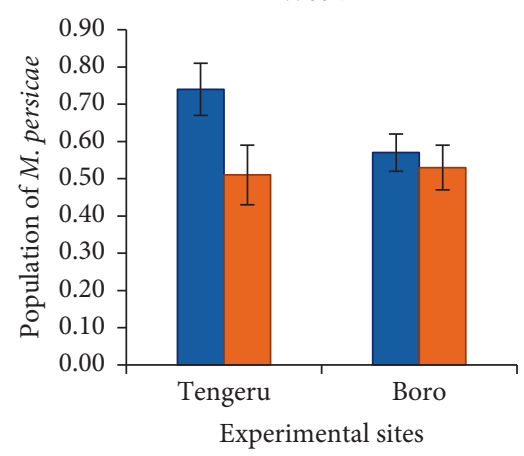

Wet season 2019

Wet season 2020
Week 2

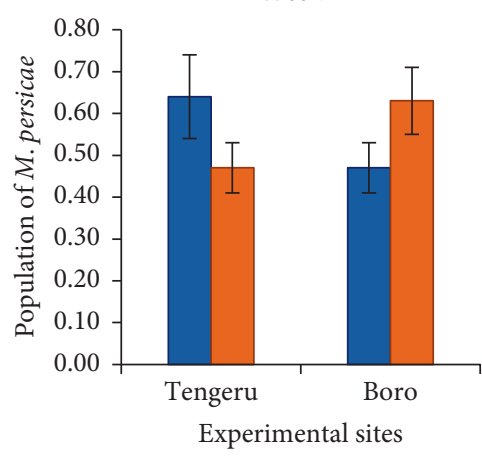

Wet season 2019

- Wet season 2020
Week 3

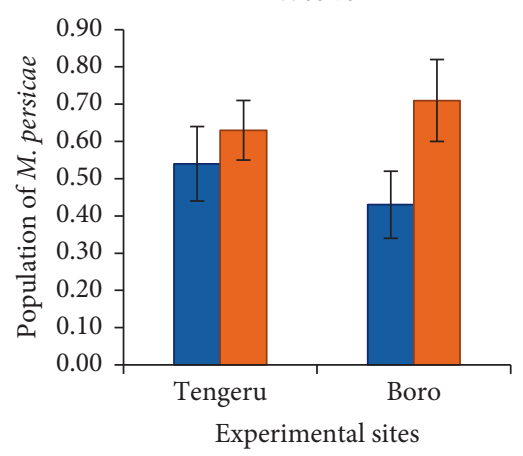

Wet season 2019

Wet season 2020

(a)

(b)

(c)

Week 4

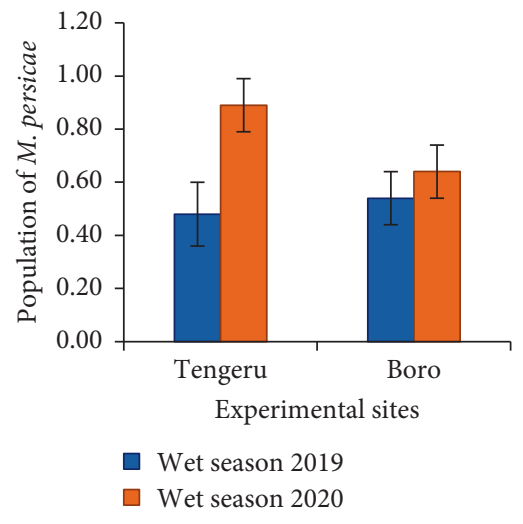

(d)

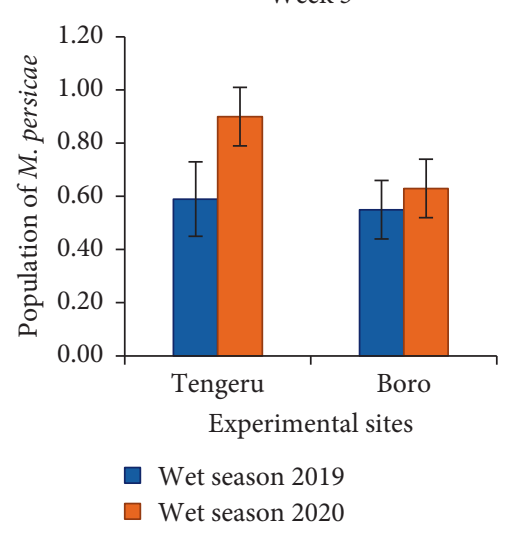

(e)

Figure 2: The interactions of weather conditions of the experimental sites and the seasons on the population abundance of $M$. persicae for 2019 and 2020 wet seasons.

Week 2

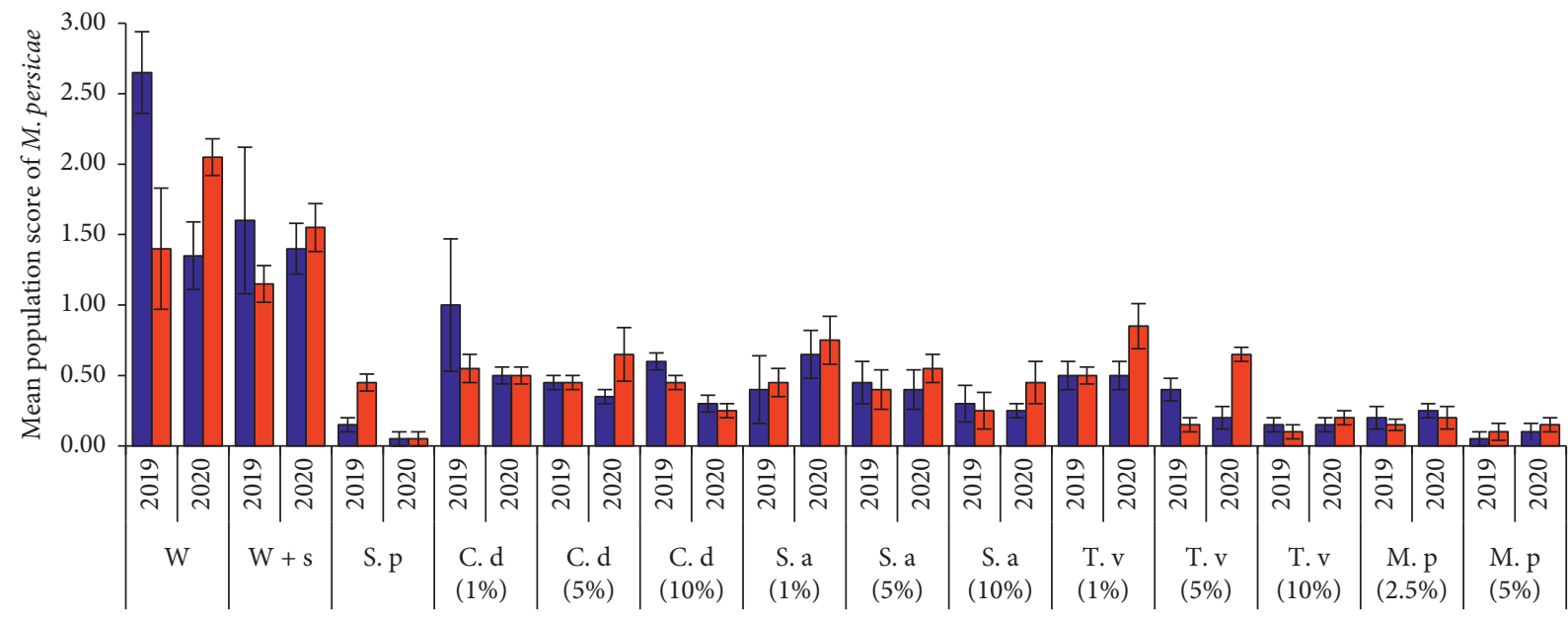

Treatments and wet seasons (2019 and 2020)

- Tengeru

․ Boro

FIgURE 3: The interactions of weather conditions of the experimental sites, wet seasons, and treatments on the mean population of M. persicae for 2019 and 2020 (week 2 after treatment). Note. C.d-Croton dichogamus, S. a-Syzygium aromaticum, T. v- Tephrosia vogelii, $\mathrm{W}$ - water, w + s- water plus soap, and S. p- synthetic pesticide. 


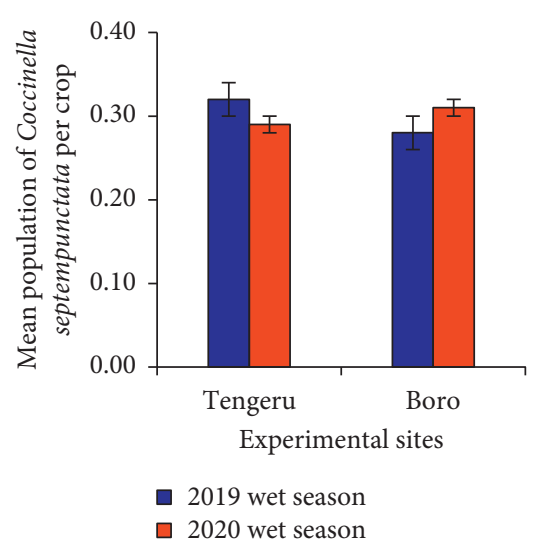

2019 wet season

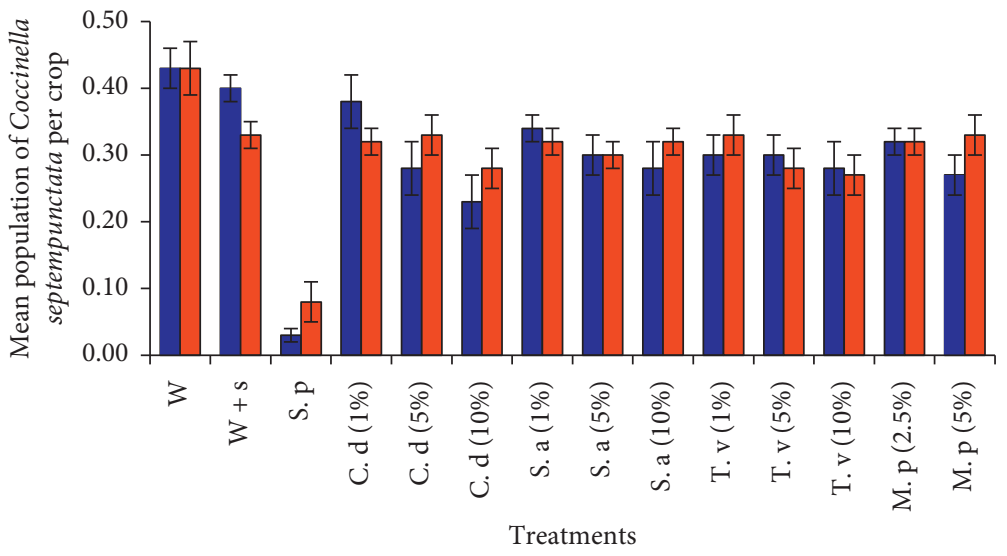

2019 wet season

2020 wet season

(a)

(b)

Figure 4: (a) Population of C. septempunctata per crop in the two wet seasons. (b) Population of C. septempunctata in response to treatments. Note. W- water, $\mathrm{w}+\mathrm{s}$ - water plus soap, S. p- synthetic pesticide, C. d-Croton dichogamus, S. a-Syzygium aromaticum, and T. $v$ Tephrosia vogelii.

the 2020 wet season compared with the 2019 wet season in both experimental sites. These variations in rainfall and temperatures could have affected significantly $(P \leq 0.05)$ the population abundance of $M$. persicae in the two seasons. As results, the population abundance of $M$. persicae was significantly $(P \leq 0.05)$ higher in the 2020 wet season than in the 2019 wet season. The results concur with the work of Patra et al. [5], which reported that M. persicae is affected either positively or negatively with rain precipitations. Similarly, the treatments applied to protect the crops from pests can work best in average rainfall.

The efficacy of the treatments of the aqueous extracts of C. dichogamus, T. vogelii, and S. aromaticum at higher concentrations (5\% concentration of aqueous extracts from mixed plants and $10 \%$ concentration from individual plants) was found to be significantly as effective as the chlorpyrifos used in this study as a positive control in managing $M$. persicae on the $B$. oleracea plants. Poor control of $M$. persicae was observed in the negative controls (water and water plus soap) plots, and the population of $M$. persicae continued to increase over time. It was found that the $5 \%$ concentrations of the aqueous extracts from the mixed plants were as effective as the synthetic pesticide (chlorpyrifos) in reducing $M$. persicae population on the B. oleracea crop. The effectiveness of the synthetic pesticide is contributed by the presence of active ingredients which persist in the environment for a long time. In addition, the differences in the effectiveness of aqueous extracts from C. dichogamus, T. vogelii, and S. aromaticum used for controlling $M$. persicae in the field could be due to differences in the chemicals present in each plant, physical properties, and the potency of active chemical compounds in the several treatments employed during the control of $M$. persicae on the field.

It was found that the $5 \%$ concentrations of the aqueous extracts from the mixed plants were as effective as the synthetic chemical pesticide (chlorpyrifos) in reducing the population of $M$. persicae on the $B$. oleracea field. The effectiveness of the synthetic pesticide is contributed by the presence of the active ingredients in it, which persist for a long time in the environment. In addition, the differences in the efficacy of aqueous extracts from C. dichogamus, $T$. vogelii, and $S$. aromaticum used for controlling M. persicae in the field could be due to differences in the chemicals present in each plant, physical properties, and the potency of active chemical compounds in the several treatments employed during the control of $M$. persicae on the field.

Moreover, it was observed that, among the aqueous extracts used, the $5 \%$ concentration of the aqueous extract of the mixed plants was significantly effective for controlling $M$. persicae in the field. The efficacy of the $5 \%$ concentration of the aqueous extract from the mixed plants might be attributed by the synergistic effects of the active chemical compounds present in the extracts of the pesticidal plants. The synergistic effects of the aqueous extracts are in agreement with the work of Tak and Isman [31], which reported that the mixture of chemicals in pesticidal plants has synergistic effects. The synergistic effect occurs when the mixture of two or more chemical compounds interacts and produces combined effects on the biological system which is greater than the algebraic sum of the effects of those chemical compounds when acting individually. Usually, plants produce secondary metabolites for defence either as distress signal to lure predators or to directly deter or repel herbivores [31]. For instance, Tak et al. [32] revealed that the binary mixture of 1,8-cineole and camphor extracted from Rosmarinus officinali exhibited enhanced insecticidal activity with a synergy ratio of 1.72 against the Trichoplusia ni larvae.

Similarly, the $10 \%$ concentration of $T$. vogelii, C. dichogamus, and S. aromaticum extracts was more effective in the reduction of $M$. persicae compared to 1 and $5 \%$. 
The efficacy of the aqueous extracts from the pesticidal plants is in agreement to other researchers [29, 33-39]. For instance, Grzywacz et al. [36] and Kamanula et al. [38] found that the effectiveness of the pesticidal plant extracts could be attributed by the presence of bioactive chemical compounds in those plants. T. vogelii, which was found effective in reducing $M$. persicae population in the present study, has been reported previously to manage ticks, lice, and flies on livestock and crops in the fields [24, 40], Plutella xylostella and Trichoplusia ni [6]. Belmain et al. [41] discovered the presence of rotenone in $T$. vogelii, which should be accountable for the insecticidal efficacy against $M$. persicae on the B. oleracea field.

Moreover, the present study found that the aqueous extracts from $S$. aromaticum significantly $(P \leq 0.05)$ lowered the population of $M$. persicae relative to negative controls (water and water plus soap). These results concur with the work of Araujo et al. [25] and Tian et al. [42]. According to Araujo et al. [25], S. aromaticum contains eugenol which could be responsible for the reduction of $M$. persicae on the $B$. oleracea crop. This study also found that aqueous extracts from Croton dichogamus significantly $(P \leq 0.05)$ lowered $M$. persicae population relative to negative controls. These results concur with those of Aldhaher et al. [28] and Silva et al. [43] who observed the presence of phenolics, terpenoids, and alkaloids in all parts of the plants, which might be accountable for the repellent, toxicity, and deterrent effects against $M$. persicae.

The population of the natural enemy, C. septempunctata, was less affected by aqueous extracts from C. dichogamus, T. vogelii, and S. aromaticum pesticidal plants (Figure 4(b)) but was severely affected by the synthetic pesticide (Figure 4(b)). These results concur with the study conducted by Amoabeng et al. [18] and Mkindi et al. [44], which reported that botanicals from pesticidal plants have little effects on nontarget organisms. The weather condition might have effects on the population of $C$. septempunctata (Figure 4(a)) because the population of C. septempunctata differed between the two wet seasons and the two experimental sites. Patra et al. [5] reported that high rainfall had a negative influence on the population of C. septempunctata in its ecosystem.

\section{Conclusions}

The pesticidal plant aqueous extracts used in the present study reduced the mean population of $M$. persicae of B. oleracea crop. Therefore, these aqueous extracts from S. aromaticum, T. vogelii, and C. dichogamus at $5 \% \mathrm{w} / \mathrm{v}$ concentrations of the mixed plant extracts and $10 \% \mathrm{w} / \mathrm{v}$ aqueous extract from each plant can be used by smallholder farmers to control $M$. persicae and reduce their infestations in B. oleracea crop.

\section{Data Availability}

The data used to support the findings of this study are available from the corresponding author upon request.

\section{Conflicts of Interest}

The authors declare no conflicts of interest regarding the publication of this paper.

\section{Acknowledgments}

The authors are grateful to the Nelson Mandela African Institution of Science and Technology, Arusha (NM-AIST), Tanzania, for providing institutional support for this study and the African Development Bank (AfDB) for funding this study. Also, they thank the Tanzania Agricultural Research Institute (TARI), Tengeru centre, Arusha, Tanzania, and Wazazi Association in Boro Village in the Kilimanjaro region, Tanzania, for providing land for establishing the study plots. Finally, they thank the technicians of the institution for field assistance and data collection.

\section{References}

[1] S. Mudzingwa, S. Muzemu, and J. Chitamba, "Pesticidal efficacy of crude aqueous extracts of Tephrosia vogelii L., Allium sativum L. and Solanum incanum L. in controlling aphids (Brevicoryne brassicae L.) in rape (Brassica napus L.)," Journal of Agricultural Research, vol. 2, no. 1, pp. 157-163, 2013.

[2] P. K. Baidoo and M. B. Mochiah, "Comparing the effectiveness of garlic (Allium sativum L.) and hot pepper (Capsicum frutescens L.) in the management of the major pests of cabbage Brassica oleracea (L.)," Sustainable Agriculture Research, vol. 5, no. 2, pp. 83-91, 2016.

[3] P. Bhagat, Y. Yadu, and V. Dubey, "Seasonal incidence and influence of environmental factors on the aphid complex on cabbage (Brassica oleracea var. capitata L.) crop," International Journal of Current Microbiological and Application Science, vol. 7, no. 3, pp. 995-1000, 2018.

[4] C. Norman and M. Shealy, Illustrated Encyclopedia of Healing Remedies, Elements Book Inc, Rockport, MA, USA, 2007.

[5] S. Patra, V. Dhote, S. Alam, B. Das, M. Chatterjee, and A. Samanta, "Population dynamics of major insect pests and their natural enemies on cabbage under new alluvial zone of West Bengal," The Journal of Plant Protection Sciences, vol. 5, no. 1, pp. 42-49, 2013.

[6] N. Mpumi, R. L. Machunda, K. M. Mtei, and P. A. Ndakidemi, "Insecticidal efficacy of Syzygium aromaticum, Tephrosia vogelii and Croton dichogamus extracts against Plutella xylostella and Trichoplusia ni on Brassica oleracea crop in northern Tanzania," AIMS Agriculture and Food, vol. 6, no. 1, pp. 185-202, 2021.

[7] A. Gibson, Colewart and the Cole Crops, University of California Los Angeles, Los Angeles, CA, USA, 2012.

[8] H. Gu, G. P. Fitt, and G. H. Baker, "Invertebrate pests of canola and their management in Australia: a review," Australian Journal of Entomology, vol. 46, no. 3, pp. 231-243, 2007.

[9] O. R. Edwards, B. Franzmann, D. Thackray, and S. Micic, "Insecticide resistance and implications for future aphid management in Australian grains and pastures: a review," Australian Journal of Experimental Agriculture, vol. 48, no. 12, pp. 1523-1530, 2008.

[10] P. A. Umina, O. Edwards, P. Carson, A. Van Rooyen, and A. Anderson, "High levels of resistance to carbamate and pyrethroid chemicals widespread in Australian Myzus persicae 
(hemiptera: aphididae) populations," Journal of Economic Entomology, vol. 107, no. 4, pp. 1626-1638, 2014.

[11] R. L. Blackman and V. F. Eastop, Aphids on the World's Crops: An Identification and Information Guide, John Wiley \& Sons Ltd., Hoboken, NJ, USA, 2000.

[12] N. Mpumi, R. L. Machunda, K. M. Mtei, and P. A. Ndakidemi, "Selected insect pests of economic importance to Brassica oleracea, their control strategies and the potential threat to environmental pollution in Africa," Sustainability, vol. 12, no. 9, pp. 1-22, 2020.

[13] I. Valenzuela and A. A. Hoffmann, "Effects of aphid feeding and associated virus injury on grain crops in Australia," Austral Entomology, vol. 54, no. 3, pp. 292-305, 2015.

[14] S. C. de Little and P. A. Umina, "Susceptibility of Australian Myzus persicae (hemiptera: aphididae) to three recently registered insecticides: spirotetramat, cyantraniliprole, and sulfoxaflor," Journal of Economic Entomology, vol. 110, no. 4, pp. 1764-1769, 2017.

[15] J. A. Anstead, J. Mallet, and I. Denholm, “Temporal and spatial incidence of alleles conferring knockdown resistance to pyrethroids in the peach-potato aphid, Myzus persicae (hemiptera: aphididae), and their association with other insecticide resistance mechanisms," Bulletin of Entomological Research, vol. 97, no. 3, pp. 243-252, 2007.

[16] M. Whalon, D. Mota-Sanchez, and R. Hollingworth, Analysis of Global Pesticide Resistance in Arthropods, CABI Publishing, Wallingford, UK, 2008.

[17] A. Seif and B. Nyambo, Integrated Pest Management for Brassica Production in East Africa, ICIPE Science Press, Addis Ababa, Ethiopia, 2013.

[18] B. W. Amoabeng, G. M. Gurr, C. W. Gitau, and P. C. Stevenson, "Cost: benefit analysis of botanical insecticide use in cabbage: implications for smallholder farmers in developing countries," Crop Protection, vol. 57, pp. 71-76, 2014.

[19] P. Koona and S. Dorn, "Extracts from Tephrosia vogelii for the protection of stored legume seeds against damage by three bruchid species," Annals of Applied Biology, vol. 147, no. 1, pp. 43-48, 2005.

[20] R. de Cássia Seffrin, I. Shikano, Y. Akhtar, and M. B. Isman, "Effects of crude seed extracts of Annona atemoya and Annona squamosa L. against the cabbage looper, Trichoplusia $n i$ in the laboratory and greenhouse," Crop Protection, vol. 29, no. 1, pp. 20-24, 2010.

[21] M. Mochiah, B. Banful, K. Fening et al., "Botanicals for the management of insect pests in organic vegetable production," Journal of Entomology and Nematology, vol. 3, no. 6, pp. 85-97, 2011.

[22] M. B. Isman, "Botanical insecticides, deterrents, and repellents in modern agriculture and an increasingly regulated world," Annual Review of Entomology, vol. 51, no. 1, pp. 45-66, 2006.

[23] N. Mpumi, K. Mtei, R. Machunda, and P. A. Ndakidemi, “The toxicity, persistence and mode of actions of selected botanical pesticides in Africa against insect pests in common beans, P. vulgaris: a review," American Journal of Plant Sciences, vol. 7, no. 1, pp. 138-151, 2016.

[24] Y. Chen, T. Yan, C. Gao, W. Cao, and R. Huang, "Natural products from the genus tephrosia," Molecules, vol. 19, no. 2, pp. 1432-1458, 2014.

[25] A. F. D. O. Araujo, J. T. Ribeiro-Paes, J. T. D. Deus et al., "Larvicidal activity of Syzygium aromaticum (L.) Merr and Citrus sinensis (L.) Osbeck essential oils and their antagonistic effects with temephos in resistant populations of Aedes aegypti," Memórias do Instituto Oswaldo Cruz, vol. 111, no. 7, pp. 443-449, 2016.

[26] G. P. Kamatou, I. Vermaak, and A. M. Viljoen, "Eugenol-from the remote maluku islands to the international market place: a review of a remarkable and versatile molecule," Molecules, vol. 17, no. 6, pp. 6953-6981, 2012.

[27] M. Mittal, N. Gupta, P. Parashar, V. Mehra, and M. Khatri, "Phytochemical evaluation and pharmacological activity of Syzygium aromaticum: a comprehensive review," International Journal of Pharmacy and Pharmaceutical Sciences, vol. 6, no. 8, pp. 67-72, 2014.

[28] A. Aldhaher, M. Langat, B. Ndunda et al., "Diterpenoids from the roots of Croton dichogamus pax," Phytochemistry, vol. 144, pp. 1-8, 2017.

[29] P. A. Mkenda, K. Mtei, and P. A. Ndakidemi, "Pesticidal efficacy of Tephrosia vogelii and Tithonia diversifolia against field insect pests of common beans [Phaseolus vulgaris L.] within African farming communities," African Journal of Applied Agricultural Sciences and Technologies, vol. 2, no. 1, pp. 9-26, 2014.

[30] J. V. K. Afun, L. E. N. Jackai, and C. J. Hodgson, "Calendar and monitored insecticide application for the control of cowpea pests," Crop Protection, vol. 10, no. 5, pp. 363-370, 1991.

[31] J. H. Tak and M. B. Isman, "Penetration-enhancement underlies synergy of plant essential oil terpenoids as insecticides in the cabbage looper, Trichoplusia ni," Scientific Reports, vol. 7, no. 1, p. 42432, 2017.

[32] J.-H. Tak, E. Jovel, and M. B. Isman, "Comparative and synergistic activity of Rosmarinus officinalis L. essential oil constituents against the larvae and an ovarian cell line of the cabbage looper, Trichoplusia ni (lepidoptera: noctuidae)," Pest Management Science, vol. 72, no. 3, pp. 474-480, 2016.

[33] S. R. Belmain, J. P. Haggar, J. Holt, and P. C. Stevenson, "Managing legume pests in sub-Saharan Africa: challenges and prospects for improving food security and nutrition through agro-ecological intensification," Technical Report, Natural Resources Institute, University of Greenwich, Gillingham, UK, 2013.

[34] S. Belmain and P. Stevenson, "Ethnobotanicals in Ghana: reviving and modernising age-old farmer practice," Pesticide Outlook, vol. 12, no. 6, pp. 233-238, 2001.

[35] T. D. T. Do Ngoc Dai, A. Ogunmoye, O. I. Eresanya, and I. A. Ogunwande, "Chemical constituents of essential oils from the leaves of Tithonia diversifolia, Houttuynia cordata and Asarum glabrum grown in Vietnam," American Journal of Essential Oils and Natural Products, vol. 2, no. 4, pp. 17-21, 2015.

[36] D. Grzywacz, P. C. Stevenson, W. L. Mushobozi, S. Belmain, and K. Wilson, "The use of indigenous ecological resources for pest control in Africa," Food Security, vol. 6, no. 1, pp. 71-86, 2014.

[37] K. Ileke and M. Oni, “Toxicity of some plant powders to maize weevil, Sitophilus zeamais (motschulsky) [coleoptera: curculiondae] on stored wheat grains (Triticum aestivum)," African Journal of Biotechnology, vol. 6, no. 13, pp. 3043-3048, 2011.

[38] J. Kamanula, G. W. Sileshi, S. R. Belmain et al., "Farmers' insect pest management practices and pesticidal plant use in the protection of stored maize and beans in Southern Africa," International Journal of Pest Management, vol. 57, no. 1, pp. 41-49, 2010.

[39] R. W. Mwanauta, K. A. Mtei, and P. A. Ndakidemi, "Prospective bioactive compounds from vernonia amygdalina, lippia javanica, dysphania ambrosioides and tithonia 
diversifolia in controlling legume insect pests," Agricultural Sciences, vol. 5, no. 12, pp. 1129-1139, 2014.

[40] M. G. Munthali, C. K. K. Gachene, G. W. Sileshi, and N. K. Karanja, "Amendment of tephrosia improved fallows with inorganic fertilizers improves soil chemical properties, $\mathrm{N}$ uptake, and maize yield in Malawi," International Journal of Agronomy, vol. 2014, pp. 1-9, Article ID 902820, 2014.

[41] S. R. Belmain, B. A. Amoah, S. P. Nyirenda, J. F. Kamanula, and P. C. Stevenson, "Highly variable insect control efficacy of tephrosia vogelii chemotypes," Journal of Agricultural and Food Chemistry, vol. 60, no. 40, pp. 10055-10063, 2012.

[42] B.-L. Tian, Q.-Z. Liu, Z.-L. Liu, P. Li, and J.-W. Wang, "Insecticidal potential of clove essential oil and its constituents on Cacopsylla chinensis (hemiptera: psyllidae) in laboratory and field," Journal of Economic Entomology, vol. 108, no. 3, pp. 957-961, 2015.

[43] C. G. Silva, J. Oliveira, and C. A. da Camara, "Insecticidal activity of the ethanolic extract from Croton species against Plutella xylostella L.(Lepidoptera: plutellidae)," Revista Facultad Nacional de Agronomía Medellín, vol. 71, no. 2, pp. 8543-8551, 2018.

[44] A. Mkindi, N. Mpumi, Y. Tembo et al., "Invasive weeds with pesticidal properties as potential new crops," Industrial Crops and Products, vol. 110, pp. 113-122, 2017. 